a higher tolerance for failure than conventional funding agencies. One idea that famously didn't make it was the hafnium bomb, based on the flawed belief that large amounts of energy can be released by bombarding the isotope hafnium-178 with X-rays.

Although DARPA's research programme managers have relatively more flexibility in what research to fund and how, no country has been able to replicate the scale of the agency's success. Even in the United States its achievements remain unrivalled. A different advanced research projects agency for new energy technologies (ARPA-E) - launched in 2009 - is under constant threat of being eliminated by the administration of President Donald Trump.

One reason why DARPA is so hard to replicate, says DARPA historian Sharon Weinberger, is because the agency's projects have a resource that the others lack. "They have a customer with the deepest pockets in the world," she says. The US Department of Defense's annual budgets for research and procurement, totalling $\$ 190$ billion, enable it to fund successful prototypes on a large scale, to test whether they might be commercially viable.

\section{Risk management}

A closer look at DARPA shows how its managers pursue bold ideas while controlling risk. In a Comment article on page 190, members of a team working with - and in the agency's Biological Technologies Office in Arlington, Virginia, report on an initiative launched in 2016. This assigns an independent validation team to projects to troubleshoot and reproduce research proposals. This 'shadow team' meets with the 'performing team' to learn the precise protocols and establish the necessary conditions to reproduce projects, and the two groups makejoint presentations to the programme manager on progress.

The work is hard - one project took as long as 20 months to reproduce. It is also expensive: it costs between $3 \%$ and $8 \%$ of a programme's funds to make sure the technologies work. But programme managers say it is worth the investment, and the model demonstrates a more careful side to the agency than DARPA's daring image tends to evoke.

These efforts are instructive, both for dreams of a UK ARPA and for science overall. Some of UK ARPA's supporters would like to see cutting-edge technologies developed within 15 years - and a certain ruthlessness when it comes to axing the least promising ones. But an ambitious technology goal in, say, regenerative medicine or remote sensing will probably need longer before careful study can make the promises - and risks - clear.

Researchers, their managers in universities, and funding agencies all understand why effective due diligence is essential to projects. But it can be difficult for these voices to be heard when no less than the prime minister's office celebrates ARPA as "high-risk, high-pay-off research", and characterizes bureaucracy as "form-filling".

Any nation looking to replicate DARPA must realize that you can't reap the rewards of high-risk research without investing in meticulous preparation and verification. The freedom to pursue bold ideas comes with added responsibility.

\section{A lack of locust preparedness}

\author{
Locusts are causing a food crisis that can no \\ longer be ignored.
}

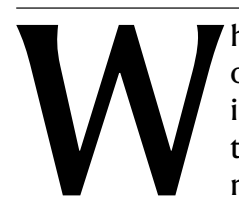

hile all eyes are on the coronavirus outbreak, an under-reported emergency is threatening food, health and jobs on three continents. For the past several months, swarms of the desert locust Schistocerca gregaria - some swarms the size of cities have devoured crops in East Africa, the Middle East and south Asia. Some 20 million people are facing a food crisis.

Governments have been left under-prepared for the scale of these attacks, and the Rome-based United Nations Food and Agriculture Organization (FAO) has appealed for US $\$ 138$ million in urgent funding - some of which is needed to lease aircraft that can drop chemicals to curb the spread.

Locusts are an annual fixture after the rainy seasonlaying their eggs in moist soils. But the size of this year's swarms - the biggest for at least 25 years - are due in part to unseasonal and often torrential rains in many areas, including Eritrea, Ethiopia, Iran, Pakistan, Saudi Arabia and Yemen. The FAO's calls must be heeded - especially as more rains are to come, bringing the potential for yet more devastation. But at the same time, some of the governments concerned must ask themselves what more they could be doing to limit the damage.

In many countries, meteorological offices share climate and weather data with what are called desert-locust-control offices. These are set up to forecast locust infestations, and to advise on potential crop losses and mitigation measures. East Africa has a regional body called the Desert Locust Control Organization for East Africa, headquartered in Addis Ababa and funded by nine African countries.

Nature has been told that some members - such as Djibouti, Somalia and Sudan - have been unable to pay their membership fees for many years and collectively owe the organization more than $\$ 8$ million. Uganda, which partially cleared its arrears last month, still owes $\$ 2$ million. Somalia and Sudan have both experienced severe conflict, so it's understandable that locusts have not been a priority. But the insects can be just as threatening to well-being, and if individual countries can't pay their way, then the African Union or the UN need to step in. Paying into locust-control offices should be regarded as keeping up an insurance policy. The hope with insurance is that it's never needed, but the facility must always be there should the need arise.

The focus now is rightly on emergency food relief. But preparations for coming swarms need to be accelerated. The African Union and the UN must ensure that countries' desert-locust organizations, informed by the latest research, are better equipped to help when the time comes. 